Journal of Intellectual \& Developmental Disability, Month Year; Volume(Issue): 1-31

Manuscript ID: CJID-2011-0084.R2

Running header: Prenatal information needs

Approximate word count: 6,953 words

Keywords: prenatal diagnosis, prenatal testing, information needs, information, decision making, Down syndrome, fragile X syndrome

ORIGINAL ARTICLE

Decision making after prenatal diagnosis of a syndrome predisposing to intellectual disability: What prospective parents need to know and the importance of non-medical information

\title{
CAROLINE HUYARD
}

Institut für Sozialforschung an der Goethe Universität, Frankfurt am Main, Germany

Correspondence: Caroline Huyard, Institut für Sozialforschung an der Goethe Universität, Senckenberganlage 26, 60325 Frankfurt am Main, Germany. E-mail: c.huyard@orange.fr 


\begin{abstract}
Background Recently researchers have suggested that non-medical information may impact the decision to continue or terminate a pregnancy after a prenatal diagnosis. This study is an investigation of what type of information prospective parents need for this decision making in the case of a condition predisposing to intellectual disability.

Method Semistructured interviews were conducted in France, Belgium, and Germany with 33 parents whose children have a syndrome that predisposes to intellectual disability.

Results The essential information related to three dimensions: (1) the foetus as a future child and an individual person; (2) the couple as future parents; and (3) the social environment of the future child and her parents, and especially the ability of the social environment to provide support.

Conclusions The findings introduce a new perspective on these prospective parents' essential needs, highlighting that these needs are not limited to medical information but encompass non-medical information and institutional patterns.
\end{abstract}

Keywords: prenatal diagnosis, prenatal testing, information needs, information, decision making, Down syndrome, fragile X syndrome 


\section{Introduction}

It is acknowledged that women and their partners need to be provided with relevant information when undergoing prenatal testing both for ethical reasons related to informed choice and for obvious practical reasons related to the nature of the decision following a positive diagnosis, for a chromosomal condition such as Down syndrome, or a congenital condition such as spina bifida. The type of information that health professionals should provide to facilitate decision making after such a diagnosis remains largely unknown. Indeed, researchers have predominantly investigated decisional needs before the prenatal tests (Durand, Stiel, Boivin, \& Elwyn, 2010; Hsieh \& Brennan, 2005; St-Jacques et al., 2008), which are complex technical procedures, and therefore difficult to explain to laypersons.

Regarding the final decision (i.e., once testing has yielded a positive result), existing studies have been focused on determining its explanatory factors. Quantitative approaches have highlighted the importance of the condition for which testing occurred (Drugan et al., 1990; Zlotogora, 2002), maternal age (Britt et al., 2000; Kramer et al., 1998), the pregnant woman's concern for the unborn child but also for herself (Korenromp, Page-Christiaens, van den Bout, Mulder, \& Visser, 2007), the future parents' knowledge of relevant health services, which seems to take precedence over their knowledge of disability (Roberts, Stough, \& Parish, 2002). In addition, researchers have relativised cultural differences and highlighted the existence of significant individual differences (Hewison et al., 2007). These findings are consistent with the results obtained by qualitative approaches, which point towards emotional dimensions related to a tension between a commitment to the pregnancy and a desire to protect the child, the couple, and the family from the hardship of disability (Bijma, van der Heide, \& Wildschut, 2008; Levy, 1999), the impact of a direct experience of the condition (France, Wyke, Ziebland, Entwistle, \& Hunt, 2011), and a concern for the quality of life of the unborn child (Ahmed et al., 2008). 
Beyond these individual emotional dimensions, the data available about pregnancy termination after a positive diagnosis outline the role of national contexts (Boyd et al., 2008) and suggest that non-medical, cultural, and institutional aspects may be worth considering. For instance, in 2006, pregnancy termination following a congenital anomaly diagnosis was more than three times higher in France (33\%), which is the second highest level in Europe after Spain, than in Germany (9\%), which is the lowest level in Europe among countries where termination is legal, and twice as high as in Belgium (15\%), the latter matching the average European level of 18\% (Ville, 2011).

Lastly, the influence of a direct or indirect experience of the corresponding disability, a neglected aspect, was recently the object of promising studies that have investigated the way an "experiential" knowledge of the relevant disability is spontaneously put to use in the context of prenatal testing (Etchegary et al., 2008; France et al., 2011). These studies included the utility of women and their partners accessing personal testimonies of people with a disability in order to be able to make an informed choice (Ahmed, Bryant, \& Hewison, 2007). The results of these studies suggested that non-medical information might play a crucial role in parents' decision to continue or terminate a pregnancy after a positive diagnosis. This area of research is worth developing in order to check whether such information could be useful, and what it should comprise.

The inquiry presented here took a specific perspective by interviewing parents who have a child with a congenital syndrome that predisposes to intellectual disability, regardless of whether they underwent prenatal testing. This approach made it possible to address a situation where interviewees have a very direct experience of the consequences of the decision to continue a pregnancy, whether they have actually made such a decision or not. Thus, interviewees are able to take a different view of the information they believe they would have needed at the time, had they had to make such a decision. The aim of this study 
was to explore the kind of information parents, whose child has an intellectual disability, considered important and useful to them for making a decision in case of prenatal diagnosis.

\section{Methodology}

The inquiry was part of a larger project that investigated the problems and requirements of recognition of people with an intellectual disability, in the sense of the German concept of Anerkennung (Honneth, 1995), which is actually closer to the ideas of appreciation and approval. In other words, the overarching question of this larger project was: What makes it possible for people to appreciate and support their fellow citizens who have an intellectual disability? Given the contemporary organisation of procreation and birth, this recognition issue had to be addressed in this study for a very early stage of life. This inquiry covered three countries: Belgium, France, and Germany.

The interviewees were recruited through self-help groups of parents whose young or adult children have an intellectual disability, or through professionals working in schools or residential centres for people with intellectual disability, with a total of eight different groups and five different professionals. Each group and professional person was sent a letter describing the research project and interview procedure. Then they circulated the letter with an invitation to potential participants to reply directly to the research investigator, who would conduct the interviews. In this letter, the interviewees were told that they were free to interrupt or terminate the interview whenever they wanted and to not answer certain questions if they did not want to without having to provide any explanation. They were told that their data would be handled confidentially and would remain anonymous. In the quoted interviews, each child's first name was systematically replaced by the most common first name for children of the same sex and age in her country. The interviewees were reminded about these points a second time just prior to the interview and asked if they agreed with them. Their agreement for the procedure was then recorded. None of the institutions, where 
the research was conducted, required a formal ethical approval. The appropriate procedure to protect the interviewees was instead defined in the French and German law, respectively, in the Code de la Santé Publique, art. L 1122-1 (2004), and in the Code Pénal, art. L 223-15-2 (2000), and in the Bundesdatenschutzgesetz, $\S 3$ and $\S 4$ (1990), and the Strafgesetzbuch, $\S$ 291 (1997). In Belgium and France the interviews were held in French, and in Germany, in German. According to the interviewees' wishes, interviews were either conducted at their home or by phone. The interviews were semistructured, audio-recorded, and transcribed. Using a 30-item guide, the interviewer addressed four main topics: (a) discovery of the syndrome, (b) parenting practices, (c) moral feelings regarding the child's behaviour, and (d) personal dimensions of the experience of having such a child. This last topic facilitated investigation of what decision interviewees would have made during the pregnancy if they had received the diagnosis at that time, although, with four exceptions, interviewees were not confronted with such a decision.

The study was based on 33 interviews conducted in Germany (13 interviews), France (12 interviews), and Belgium (eight interviews) between 2008 and 2010 among women, men, or couples who had at least one child with either fragile X syndrome (15 interviews), Down syndrome (15 interviews), Williams syndrome (two interviews), or a congenital diaphragmatic hernia (one interview). Prior to their child's diagnosis, parents of children with fragile X syndrome were not aware of other cases in the family. The interviewees were predominantly women ( 25 interviewees), but there were eight male interviewees $(25 \%$ of the interviewees). Four (12\%) of the interviewees had experienced a prenatal diagnosis; that is, in three cases the pregnancy was continued, and in one case it was terminated because the couple already had a child with an intellectual disability. The recruitment of the interviewees was carried out sequentially, in order to obtain a sample that was representative of the general population of each of the three countries in terms of the participants' professional occupation. 
However, unavoidably, the interviewees were somewhat more educated and skilled than the general population.

$<$ Please insert Table 1 about here $>$

Other important characteristics of the interviewees that could have been expected to play a role in decision making are age of the mother at the time of the birth of her child with a disability (Britt et al., 2000; Kramer et al., 1998), marital status, and rank of the child amongst siblings (Levy, 1999). These characteristics are summarised in Tables 2, 3, and 4.

$<$ Please insert Table 2 about here $>$

$<$ Please insert Table 3 about here $>$

$<$ Please insert Table 4 about here $>$

Data analysis was performed using classical grounded theory methods (Corbin \& Strauss, 2008). The coding process started by labelling "a distressing decision" regarding pregnancy continuation or termination, and accordingly investigated what caused this distress. Coding the data with respect to the decision making highlighted the importance of three types of information, namely: (1) the foetus as a future child and individual person; (2) the couple as future parents; (3) the social environment of the future child and her parents, and especially the capacity of this environment to support them. Currently, none of these three types of information is available to parents at the time of the decision.

\section{Findings}

The sociodemographic dimensions presented in Table 1, 2, 3, and 4 did not account for differences between the interviewees. Instead, the key reasons for the decision they would have taken related to informational needs and issues. Reflecting on the experience of bringing up a child with intellectual disability, the interviewees concluded that three main types of information would be needed by prospective parents in order to make the decision to continue or to terminate a pregnancy after a prenatal diagnosis: (1) the foetus as a future child and 
individual person; (2) the couple as future parents; (3) the social environment of the future child and her parents, and especially its capacity to support them. The interviewees' justifications varied, depending on whether they believed they would have continued or terminated the pregnancy or whether this remained an impossible decision for them. These three categories of information are presented in relation to the decision the interviewees retrospectively think they would have made.

Continuing the pregnancy: Parenting first and foremost means accepting the children, whatever their medical characteristics

Thirteen parents stated that, had they known about their child's syndrome at a prenatal stage, they would have continued the pregnancy. Four parents had experienced this situation: their child's syndrome was diagnosed during the pregnancy and they had kept the baby in three cases, and one mother wished she had not terminated a pregnancy.

In most of these interviews (10 of 13), the justifications referred to a personal view of what parenting is and implies, namely, to accept children as they are (five interviews), and to the desire of having a child and accepting him or her however he or she may be (five interviews). Parenting is the key issue. Three interviewees provided slightly different justifications. In two interviews, the parents considered that even though their child has a syndrome that hampers her or his learning ability, this was not serious enough to justify a pregnancy termination. In a third interview, a mother explained that she gradually discovered her own ability to care for her child. Her inability to provide this care would have been the justification for termination of the pregnancy.

The view of parenting that supports pregnancy continuation for these parents is sometimes related to religious belief, as was the case for three interviewees. However, such a view was also expressed without any religious reference in two interviews, as demonstrated by this woman (France) whose 6-year-old son has fragile $\mathrm{X}$ syndrome: 
I cannot say whether I would have let Thomas go away or not, I cannot say that now. To make a guess, I would say no, no, it would be no. Thomas would have had an ear missing or an arm missing, it would have been no. Thomas is Thomas.

The importance of the decision of having or keeping a child is best illustrated by two interviewees who were told that their child had Down syndrome, as they were themselves in complicated situations (i.e., out of a stable relationship in one case and affected by a still developing but potentially very serious illness in the other case). These interviewees decided to continue the pregnancy. The circumstances of their pregnancy had led them to ask themselves if they wanted to keep the child or not. They had chosen to keep the child, and did not change their mind when they received the diagnosis for Down syndrome. This woman from Germany whose 3-year-old daughter has Down syndrome explained:

She was not really a desired child. And so the question arose, before I even knew she had Down syndrome, to keep this child or not. I said yes. Then she was diagnosed with Down syndrome. And this took me back to the same question. And I thought in the end ... Who am I to decide if this child will live or not? I'm only a human being.

These justifications for the continuation of the pregnancy do not take into account the medical information that may have been provided through prenatal diagnosis. These interviewees either unconditionally decided to have a child, which many of them expressed by saying "we take children as they come," or they considered that the issues to be taken into account were the "the foetus as an individual child," "being able to cope as a couple and as parents," and "being provided assistance."

The importance of the foetus as an individual child is apparent in the case of a man (Germany) whose 14-year-old daughter was diagnosed with a congenital anomaly during the second trimester of pregnancy. To help this couple in their decision, the question they needed 
an answer to was the future of this particular child and not the syndrome:

For one thing, a friend [...] called my wife and said, 'ask the child in your belly if she wants to live.' And just then, the child [...] protested loudly; that is, she kicked and fidgeted thoroughly. Then, the evening before the day when we had to decide if we would continue or interrupt the pregnancy, I said, 'Big Boss, I can't make the decision. I'm lost, so give me a sign.' It had really nothing to do with morals. I said, 'if the child must live, then tomorrow morning, before 7 a.m., send a doctor who will tell my wife that we should continue the pregnancy.' And on the next day, at 8 a.m., I called my wife at the hospital and she told me that at 7 a.m., the doctor had told her, 'forget about the abortion. I've the feeling that it will be all right with the child.' And we said, 'okay, fine. We'll do that and accept it.'

The second crucial theme for the interviewees was their ability to cope as parents. It is highlighted here by a woman (Germany) whose son, born in 1991, was diagnosed very early with fragile X syndrome, at a time when she was pregnant for a second time. Prenatal diagnosis was therefore performed very swiftly:

[The doctors] said that the child would certainly be more seriously affected than Kevin, which was an additional shock. I had to make a decision relatively quickly. And the father said at the time that he did not want another disabled child, he felt he wouldn't be able to cope. And so, I let myself be influenced, because apart from of my parents and Kevin's father, I have nobody. I said okay, maybe it is better not to keep the child. And I must say that I immensely regret it. I have regretted it to this day, because finally ...Why [should I have not kept the child]? [...] Of course, it would have been different. But Kevin would have had a brother! This would have been good. I have very often thought, my God, even with a second child, I'd have 
made it. Sure, I would have had to restrict myself. It would have been difficult, but he would have had a brother! And that, I really ... Well ... Yes. I regretted it.

Lastly, the interviewees expressed concern for the assistance provided by a range of social institutions for parents of children with disability, especially dedicated schools, homes, and workplaces. This was a major issue for this woman (France) whose 23-year-old son has Williams syndrome:

As I often say, medicine has made progress, and nowadays makes it possible for children with some difficulties, children who would not have lived, to live. But society has made no progress! Because society takes care of the children until they're 18-20 year old, and then, there's no money, no more school, and we're told to manage by ourselves. This is why, sometimes, I say, we'd better not bear them. It's hard.

Medical information was not considered very important for decision making by these interviewees. Neither was it for the interviewees who said they would have taken the opposite decision.

Terminating the pregnancy: When the lack of social support turns maternal parenting into too heavy a burden

Eight parents noted that had they known about their child's syndrome at a prenatal stage, they would have terminated the pregnancy. In six of these interviews, the common justification was that the essential support, needed by the parents to bring up the child with intellectual disability, was not appropriate; the type of support was different from one interview to another, and two interviewees provided no justification.

Six interviewees were not concerned about the foetus as an individual child but worried deeply about their ability to cope as parents and the social environment of the child with respect to the capacity of this environment to support the child after their death. Some 
female interviewees connected their ability to cope as parents to the support available from the child's father, although the seven female interviewees who brought up their child alone did not all say that they would have preferred terminating their pregnancy because this support was not available. In two interviews, however, this was the case, as a woman (Belgium) whose younger son, aged 27, has fragile X syndrome explained:

Ah, I wouldn't have kept him. Maybe you can't see it now, but well, I had to cope with quite a lot of things all alone. It's not ... I don't know if it's actually much easier, people say it is not much easier when people cope as a couple, because when one says black, the other says white. Maybe. But in a couple, you're two people, and you can help each other, carry each other, when there's two of you ...

The interviewees shared an anxiety about what their children's life will be like as adults and especially after their parents' death. An appropriate, supportive, social environment is a key concern for decision making. Two of the interviewees refer to this anxiety when making a case for pregnancy termination, such as this woman (France), whose 12-year-old daughter has Down syndrome:

I would abort. Sure. [...] It wouldn't be because of the everyday difficulties, although they exist and we have a different life. But the biggest issue for me, it's what happens to these children after their parents' death, what their future will be like. That's what I'm afraid of. And that's why, if I had the choice now, and if I had had the choice, I would have aborted.

These issues, coping as a couple and a supportive social environment, intertwine in more particular personal situations or views. One of the interviewed women (France) has to look after her ailing father as well as her sister who also has an intellectual disability. This interviewee explained that because of this family responsibility, she would have preferred to 
avoid having a son with a disability. Another woman (Germany) said she would have terminated the pregnancy, firstly, "for her" and, secondly, for her 34-year-old son, whom she considers a burden and whose life she views as not worthwhile. She was divorced at the time of the interview, and said her husband had always borne the bulk of the education of their two children. This view relates both to the ability to cope and to the social environment, as it is apparent in her explanations:

I would have aborted. Well, I would say, for me. For me. But in the first place, for him, because, as I often say, what happens to him, when his parents are not there anymore? And his sister doesn't want to have anything to do with her brother. I always wonder, what happens to these children when the parents are not there anymore? What do they feel, if they feel anything? I don't know. We can express what we want to do. But they are always told to do this and that. What kind of life is it? Is it worth it? So, had I been able to, I would have aborted, full stop.

These justifications did not take medical information, which may have been provided through prenatal diagnosis, into account. The questions that parents feel they are confronted with are different: they relate both to a supportive social environment, especially with respect to the child's future, and to their own capacity to bring up such a child.

Remaining irresolute: When the essential information for making a decision is not available Lastly, 12 interviewees were unable to say whether they would have continued with the pregnancy or not. In these interviews (except for one, where the interviewee provided no justification), these parents' indecision resulted from their being acutely aware that the information they considered as essential to make this decision was not available.

The first fundamental element of missing information is, according to two interviewees, the personality and the individual abilities of the child. At the time of the 
interviews, these parents had learnt a lot about their child, and not only that he or she had a particular syndrome, but also that they had often had the opportunity to notice that two persons with the same syndrome were very different and had different abilities. As a woman (France) with a 32-year-old daughter with Down syndrome explained:

Now, since Stephanie is actually what she is, I would tend to say, I did well [to continue the pregnancy]. But when you see other people with Down syndrome who have other problems, who are in much worse situations ... I think ... It's a difficult choice. [...] Today, Stephanie is thirty-two, I can see how far she has gone in life, so I see things differently.

A man (Belgium) whose 16-year-old daughter has Down syndrome similarly insisted on the importance of the child's personality:

It's difficult to go back in time and say what I would have done. Now ... I lived with my daughter, and I would not like a different life. I'm happy that I had Laura and not another child. [...] Because I've changed. I see things differently now. I have lived with Laura, I have met people with a disability, so the way I see things has changed.

A second crucial element, mentioned by seven interviewees, related to the parents' ability for parenting. Had they known about the syndrome during pregnancy, they believe they would have been plagued by fear, considering themselves either unable to meet the child's emotional, affective, and educational needs, or to face this unknown situation. The interviewees reported that this fear, which they somehow experienced when the child was diagnosed, disappeared as the child grew and as they realised they were actually able to cope. However, this information was not available for a decision at the time of pregnancy. For instance, the concern for what life would be like with such a child was an issue for a man (Belgium) whose 16-year-old son has Down syndrome: 
Imagine we're back to the starting point, and we don't know what we know now, I think we would not have been through. Now, with what we have experienced, finally, I would say it is not as complicated as one could have thought. And I think there would have been no worries

The ability to cope was also a major question for this woman (France) whose 17-yearold son has Down syndrome:

I did not know, and I did without knowing. Besides, I'm sure there are lots of things that we don't know. We don't know what we are up to, how resourceful we actually are ... I think, these nine months, I don't know ... Maybe I would have reacted well, maybe I would have done things differently ... But I had nine months of happiness, and Kevin had nine months of happiness too, nobody asked any questions. Because when I see ... I see my little daughters-in-law and their pregnancies, it was really medicalised. And I see some of my colleagues who had tests, they suspected there was something wrong, it is incredibly distressing. I think ... It scares me. It's exaggerated. Because I mean, anyway ... I do not think this is denial, I mean, if you look at life with a certain perspective, everything is so risky that you no longer feel up to anything.

The contrast between the interviewees' ignorance about the essential elements for decision making at prenatal stage and the way these elements became naturally available over the years builds the core of the dilemma parents face with prenatal testing.

Anxieties regarding the quality and the availability of institutional support were quite present, as exemplified by this woman (France) whose 14-year-old daughter has fragile $\mathrm{X}$ syndrome:

I don't know, I really don't know. [...] When you've got children, you look at how 
well they do at school. And then, they say 'I'd like to do this' or 'I'd prefer to do that job.' But I say, my daughter has no choice [she pauses]. People will decide for her. They will impose decisions on her. [With tears in her eyes] I stopped my studies, because I didn't want to continue! But she cannot decide. She cannot. I'm sure that when she's 20 , she'll have to go either in a home for disabled people or in a specific workplace. But you can't get a job without relationships, so, she'll have no choice, and she'll have to go in a home. There's no hope. No hope.

This highlights that prenatal decision making rests on a major contradiction. Over the years following the child's birth, parents have gained information that would have enabled them to decide, with confidence, about the pregnancy. However, the problem they face and ultimately cannot solve is the fact that they would actually have been forced to decide without this information.

\section{Discussion}

The findings are the result of a study that covers two syndromes in three countries, which ensured that the findings did not relate to only one particular syndrome or national context. The interviews were performed at a time when the interviewees were no longer in a situation of distress resulting from diagnosis disclosure and could reflect upon their past experience. The findings of this study support the insight that non-medical information is a decisive factor in decisions about the continuation or termination of a pregnancy after a positive diagnosis for a syndrome that predisposes to intellectual disability. The identified informational needs are consistent with the results of different qualitative studies about decision making at the prenatal testing stage. Some studies highlighted the influence of the future quality of life of the unborn child (Ahmed et al., 2008), which relates to the need for information about the child as an individual person, as identified in this study. Some researchers underlined the influence of the self-interested motives of the prospective mother 
(Korenromp et al., 2007), which relates to the informational need about the prospective parents as parents identified here. Lastly, other studies highlighted the influence of the prospective parents' knowledge of relevant health services (Roberts et al., 2002), which relates to the informational need about the available support for the future family as identified in this study. In addition, the views expressed by interviewees match the respective national statistics; the German interviewees said they would have continued the pregnancy more often than the French and the Belgian interviewees (Ville, 2011).

The number of interviewees who said they would have continued the pregnancy (13) may seem high in comparison with the number of interviewees who said they would have terminated the pregnancy (eight). It is therefore necessary to investigate if a post hoc rationalisation could have taken place (i.e., if some parents who have and live with a child with a disability have tried to reduce a cognitive dissonance and provided a biased answer). Fortunately, the data allowed us to compare the answers of parents who said they would have kept the child if they had known about the syndrome at the prenatal stage with the answers of parents who did know about the syndrome and kept the child. It appears that the typical justification tends to be the same: when the decision to have a child has been made, the characteristics of the child are not important. Thus, a father who had to make a decision at the prenatal stage explained:

When I work with people, I don't work with percentage. I say: 'it is your decision, you have to put up with making a decision, and you have to make your own decision. [...] No mathematics, no study, no scientific book will help you. It's your own decision. That's what my daughter taught me.

Similarly, a mother who did not have to make such a decision said: "Statistics are complex, and for the parents, it does not change much. An accident can always happen. 
Those who don't accept risks should not have children!" The point in this study is not to know what people would actually have done, but to find out what they would base their decision on. The similar line of reasoning of these two categories of parents within the group of interviewees, who said they would have kept the child, is, in this perspective, reliable.

The importance of the three types of non-medical information has crucial theoretical implications for the decision-making process. This finding highlights that an appropriate recognition theory should consider as crucial the failure to identify the decisive role of the person who "recognises" and the social environment where the recognition takes places, and not so much the characteristics of the "recognised" person. This is consistent with previous studies, although here a different perspective was adopted with different implications. A number of disability studies have criticised the views that focus on individual medical characteristics and insist on the social dimensions of disability (Asch, 1999; Parens \& Asch, 2003). The main finding of this study goes further and suggests how important it is to describe and analyse the support needed by those who have to care for people with a disability. Empowering these caregivers is a stepping stone towards recognition of people with a disability, in addition to being a major practical concern. This point is particularly apparent in the group of interviewees who said they would have terminated the pregnancy; the majority of them referred to a lack of social support on which to ground this decision. The caregivers' needs are most important since traditional explanatory factors such as the parents' professional background, the mother's age or matrimonial status did not appear to play an important role in this study. The parents' needs seem to be related to very individual situations and individual biographies.

Ten interviewees reported that their main concern at the time of the disclosure of the diagnosis related to what their child would be able to do as an adult. This is the only piece of information they asked medical professionals about. Yet this, unfortunately, is a question that 
could not be answered. Other essential information, however, could be provided. This study supports the view that expectant parents need information regarding available social support as well as their own ability to cope. This has important practical implications. Meeting the prospective parents' informational needs requires data that cannot usually be provided by medical staff and is rarely available during pregnancy since it relates to a future state of the individual child and of the parents and, to a lesser extent, of society. This finding supports the view that it could be useful for professionals and lay people, who are familiar with the everyday life aspects of disability, to assist medical staff by bridging the traditional divide between perinatal medicine and disability policies (Ville, 2011). Prospective parents need to be provided with information about the life of a family with a child who has the corresponding syndrome in order to substantiate their own reflections about the child, themselves, and the available social support. Such information could be based on a range of testimonies covering different and contrasting experiences, as well as different aspects of daily life, including statistical data about the development of the child's abilities as they grow up. Today's digital technologies make access to a range of information possible, and users can choose the type and the amount of information they wish to have, according to their own needs. 


\section{Note}

$1[\ldots]$ is used in the transcripts to indicate the suppression of a passage that was too long and not relevant to the discussion.

$\ldots$ is used when the interviewee did not finish the sentence or paused briefly. 


\section{Acknowledgements}

I am grateful to Nick Jones for proofreading this text, and to two anonymous reviewers,

whose comments strongly contributed to improve the manuscript. I very warmly thank all the interviewees for their contribution. 


\section{Author note}

This research project was supported by a Marie Curie Intra European Fellowship within the 7th European Framework Programme and by the Maison des Sciences de l'Homme and the Thyssen Stiftung through a joint Clemens Heller grant. The funding bodies have imposed no restriction on free access to or publication of the research data. The author declares no financial and nonfinancial conflict of interest. 


\section{References}

Ahmed, S., Bryant, L., \& Hewison, J. (2007). 'Balance' is in the eye of the beholder: Providing information to support informed choices in antenatal screening via Antenatal Screening Web Resource. Health Expectations, 10, 309-320. doi:10.1111/j.1369-7625.2007.00455.x

Ahmed, S., Hewison, J., Green, J. M., Cuckle, H. S., Hirst, J., \& Thornton, J. G. (2008). Decisions about testing and termination of pregnancy for different fetal conditions: A qualitative study of European white and Pakistani mothers of affected children. Journal of Genetic Counseling, 17, 560-572. doi:10.1007/s10897-008-9176-x

Asch, A. (1999). Prenatal diagnosis and selective abortion: A challenge to practice and policy. American Journal of Public Health, 89, 1649-1657. doi:10.2105/AJPH.89.11.1649

Bijma, H. H., van der Heide, A., \& Wildschut, H. I. J. (2008). Decision-making after ultrasound diagnosis of fetal abnormality. Reproductive Health Matters, 16, 82-89. doi:10.1016/S0968-8080(08)31372-X

Boyd, P. A., DeVigan, C., Khoshnood, B., Loane, M., Garne, E., \& Dolk H., \& the EUROCAT Working Group (2008). Survey of prenatal screening policies in Europe for structural malformations and chromosome anomalies, and their impact on detection and termination rates for neural tube defects and Down's syndrome. BJOG, 115, 689-696. doi:10.1111/j.1471-0528.2008.01700.x

Britt, D. W., Risinger, S. T., Miller, V., Mans, M. K., Krivchenia, E. L., \& Evans, M. I. (2000). Determinants of parental decisions after the prenatal diagnosis of Down syndrome: Bringing in context. American Journal of Medical Genetics, 93, 410-416. doi:10.1002/1096-8628(20000828)93:5<410::AID-AJMG12>3.0.CO;2-F

Bundesdatenschutzgesetz, $\S 3$ and $\S 4$ (1990). Retrieved from http://www.gesetze-iminternet.de/index.html 
Code de la Santé Publique, art. L 1122-1 (2004). Retrieved from http://www.legifrance.gouv.fr

Code Pénal, art. L 223-15-2 (2000). Retrieved from http://www.legifrance.gouv.fr

Corbin, J., \& Strauss, A. (2008). Basics of qualitative research: Techniques and procedures for developing grounded theory (3rd ed.). Thousand Oaks, CA: Sage.

Drugan, A., Greb, A., Johnson, M. P., Krivchenia, E. L., Uhlmann, W. R., Moghissi, K. S., \& Evans, M. I. (1990). Determinants of parental decisions to abort for chromosome abnormalities. Prenatal Diagnosis, 10, 483-490. doi:10.1002/pd.1970100802

Durand, M.-A., Stiel, M., Boivin, J., \& Elwyn, G. (2010). Information and decision support needs of parents considering amniocentesis: Interviews with pregnant women and health professionals. Health Expectations, 13, 125-138. doi:10.1111/j.13697625.2009.00544.x

Etchegary, H., Potter, B., Howley, H., Cappelli, M., Coyle, D., Graham, I., ... \& Wilson, B. (2008). The influence of experiential knowledge on prenatal screening and testing decisions. Genetic Testing, 12, 115-124. doi:10.1089/gte.2007.0057

France, E. F., Wyke, S., Ziebland, S., Entwistle, V. A., \& Hunt, K. (2011). How personal experiences feature in women's accounts of use of information for decisions about antenatal diagnostic testing for foetal abnormality. Social Science \& Medicine, 72, 755-762. doi:10.1016/j.socscimed.2010.11.031

Hewison, J., Green, J. M., Ahmed, S., Cuckle, H. S., Hirst, J., Hucknall, C., \& Thornton, J. G. (2007). Attitudes to prenatal testing and termination of pregnancy for fetal abnormality: A comparison of white and Pakistani women in the UK. Prenatal Diagnosis, 27, 419-430. doi:10.1002/pd.1701

Hsieh, Y., \& Brennan, P. F. (2005). What are pregnant women's information needs and information seeking behaviors prior to their prenatal genetic counseling? AMIA 
Annual Symposium Proceedings Archive, 2005, 355-359.

Honneth, A. (1995). The struggle for recognition: The moral grammar of social conflicts. Cambridge, MA: MIT Press.

Korenromp, M. J., Page-Christiaens, G. C. M. L., van den Bout, J., Mulder, E. J. H., \& Visser, G. H. A. (2007). Maternal decision to terminate pregnancy in case of Down syndrome. American Journal of Obstetrics and Gynecology, 196, 149.e1-149e.11.

Kramer, R. L., Jarve, R. K., Yaron, Y., Johnson, M. P., Lampinen, J., Kasperski, S. B., \& Evans, M. I. (1998). Determinants of parental decisions after the prenatal diagnosis of Down syndrome. American Journal of Medical Genetics, 79, 172-174. doi:10.1002/ (SICI)1096-8628(19980923)79:3<172::AID-AJMG4>3.0.CO;2-P

Levy, V. (1999). Maintaining equilibrium: A grounded theory study of the processes involved when women make informed choices during pregnancy. Midwifery, 15, 109-119. doi:10.1016/S0266-6138(99)90007-4

Parens, E., \& Asch, A. (2003). Disability rights critique of prenatal genetic testing: Reflections and recommendations. Mental Retardation and Developmental Disabilities Research Reviews, 9, 40-47. doi:10.1002/mrdd.10056

Roberts, C. D., Stough, L. D., \& Parrish, L. H. (2002). The role of genetic counseling in the elective termination of pregnancies involving fetuses with disabilities. Journal of Special Education, 36, 48-55. doi:10.1177/00224669020360010501

St-Jacques, S., Grenier, S., Charland, M., Forest, J.-C., Rousseau, F., \& Légaré, F. (2008). Decisional needs assessment regarding Down syndrome prenatal testing: A systematic review of the perceptions of women, their partners and health professionals. Prenatal Diagnosis, 28, 1183-1203. doi:10.1002/pd.2059

Strafgesetzbuch, § 291 (1997). Retrieved from http://www.gesetze-im-internet.de/index.html Ville, I. (2011). Disability policies and perinatal medicine: The difficult conciliation of two 
Prenatal information needs

fields of intervention on disability. Alter, 5, 16-25. doi:10.1016/j.alter.2010.11.002 
Zlotogora, J. (2002). Parental decisions to abort or continue a pregnancy with an abnormal finding after an invasive prenatal test. Prenatal Diagnosis, 22, 1102-1106. doi:10.1002/pd.472 
Prenatal information needs

Table 1. Professional occupation

\begin{tabular}{lcc}
\hline & Number of interviewees & Percentage of interviewees \\
\hline Senior executives & 5 & 15.2 \\
Supervisors & 9 & 27.2 \\
Workers or office clerks & 10 & 30.3 \\
Independent & 4 & 12.1 \\
No professional occupation & 5 & 15.2 \\
\hline Total & 33 & 100 \\
\hline
\end{tabular}


Table 2. Age of the mother at the time of the birth and age of the child at the time of the inquiry

\begin{tabular}{lccccc}
\hline $\begin{array}{l}\text { Age of the mother at } \\
\text { the time of the birth }\end{array}$ & $\begin{array}{c}\text { Number of } \\
\text { interviewees }\end{array}$ & $\begin{array}{c}\text { Percentage of } \\
\text { interviewees }\end{array}$ & Age of the child & $\begin{array}{c}\text { Number of } \\
\text { children }\end{array}$ & $\begin{array}{c}\text { Percentage } \\
\text { of children }\end{array}$ \\
\hline 20-25 years & 5 & 16 & Less than 7 years & 4 & 11 \\
$26-30$ years & 9 & 29 & $7-11$ years & 7 & 19 \\
$31-35$ years & 10 & 32 & $12-20$ years & 19 & 51 \\
$36-40$ years & 7 & 23 & Older than 20 & 7 & 19 \\
\hline Total & 31 & 100 & Total & 37 & 100 \\
\hline
\end{tabular}


Prenatal information needs

Table 3. Interviewees' marital status

\begin{tabular}{lcc}
\hline Interviewees' marital status & Number of interviewees & Percentage of interviewees \\
\hline Married or in cohabitation & 25 & 76 \\
Separated or divorced & 6 & 18 \\
Widow(er) & 2 & 6 \\
\hline Total & 33 & 100 \\
\hline
\end{tabular}


Prenatal information needs

Table 4. Rank of the child with a disability amongst siblings

\begin{tabular}{lcc}
\hline & Number of children & Percentage of children \\
\hline No siblings & 7 & 19 \\
Youngest child & 16 & 43 \\
Child in the "middle" position & 9 & 24 \\
Eldest child & 5 & 14 \\
\hline Total & 37 & 100
\end{tabular}

